\title{
Biochemical characteristics of AtFAR2, a fatty acid reductase from Arabidopsis thaliana that reduces fatty acyl-CoA and -ACP substrates into fatty alcohols
}

\author{
Thuy T. P. Doan ${ }^{2 \bowtie}$, Anders S. Carlsson 1 , Sten Stymne ${ }^{1}$ and Per Hofvander ${ }^{1}$ \\ 1Department of Plant Breeding, Swedish University of Agricultural Sciences, P.O. Box 101, 23053 Alnarp, Sweden; 2Department of Biology, \\ Faculty of Science, Nong Lam University, Ho Chi Minh City, Vietnam
}

Fatty alcohols and derivatives are important for proper deposition of a functional pollen wall. Mutations in specific genes encoding fatty acid reductases (FAR) responsible for fatty alcohol production cause abnormal development of pollen. A disrupted AtFAR2 (MS2) gene in Arabidopsis thaliana results in pollen developing an abnormal exine layer and a reduced fertility phenotype. AtFAR2 has been shown to be targeted to chloroplasts and in a purified form to be specific for acyl-ACP substrates. Here, we present data on the in vitro and in planta characterizations of AtFAR2 from A. thaliana and show that this enzyme has the ability to use both, C16:0-ACP and C16:0-CoA, as substrates to produce C16:0-alcohol. Our results further show that AtFAR2 is highly similar in properties and substrate specificity to AtFAR6 for which in vitro data has been published, and which is also a chloroplast localized enzyme. This suggests that although AtFAR2 is the major enzyme responsible for exine layer functionality, AtFAR6 might provide functional redundancy to AtFAR2.

Key words: Arabidopsis thaliana, chloroplast, fatty acyl-CoA/ACP reductase, fatty alcohol, fatty aldehyde

Received: 01 January, 2016; revised: 04 February, 2016; accepted: 16 February, 2016; available on-line: 08 June, 2016

\section{INTRODUCTION}

Very long chain primary fatty alcohols are important structural components in cuticle waxes and suberin of plants (Rowland et al., 2006; Domergue et al., 2010; Rowland \& Domergue, 2012). Together with other substances of the cuticle waxes and suberin, primary alcohols provide the hydrophobic layer that protects plants from pathogens, abiotic stresses and furthermore influence plant anatomy and morphology (Post-Beittenmiller, 1996; Pollard et al., 2008; Chen et al., 2011; Shi et al., 2011).

The biosynthesis of fatty alcohols from acyl-CoA is catalyzed by fatty acyl-CoA reductases (FAR) in two consecutive reactions. Fatty acyl-CoA is first reduced into a fatty aldehyde which is followed by a second reduction of fatty aldehyde into fatty alcohol (Kolattukudy, 1970; Vioque \& Kolattukudy, 1997). It has been found that under in vivo conditions in plants, the reduction of fatty acyl-CoA into fatty alcohol is generally carried out by a NADPH-dependent FAR enzyme without releasing an aldehyde intermediate (Vioque \& Kolattukudy, 1997; Metz et al., 2000; Wang et al., 2002; Rowland et al., 2006; Domergue et al., 2010); however the intermediate aldehyde can be observed under in vitro conditions
(Doan et al., 2012). Arabidopsis has been found to contain eight different loci encoding putative FARs (Domergue et al., 2010; Doan et al., 2012; Chacon et al., 2013). Two of the FAR genes in Arabidopsis have been determined to encode chloroplast localized enzymes, AtFAR2 and AtFAR6 (Chen et al., 2011; Doan et al., 2012). The chain lengths and distribution of fatty alcohols is diverse in plants and are controlled by the substrate specificities of particular FARs, as well as by their spatial domain of gene expression (Vioque \& Kolattukudy, 1997; Metz et al., 2000; Wang et al., 2002; Rowland et al., 2006; Domergue et al., 2010). The ms 2 mutant of Arabidopsis displays a male sterile phenotype (Aarts et al., 1997) although it is more of a reduced fertility genotype (Dobritsa et al., 2009). The corresponding AtFAR2 (MS2) gene has been found to be involved in the production of fatty alcohols for building the structure of the exine layers of sporopollenin (Aarts et al., 1997; Dobritsa et al., 2009; Chen et al., 2011). This enzyme was recently characterized as being very specific for the production of C16:0alcohol from C16:0-ACP, but with no activity towards C16:0-CoA (Chen et al., 2011). In this report, we present data on the experiments which conclusively show that AtFAR2 has the ability to use both, C16:0-ACP and C16:0-CoA substrates for the production of C16:0alcohol. Our results thus show that AtFAR2 has further similarities to the published properties of AtFAR6 in substrate specificity that differentiate them from other Arabidopsis FARs. This suggests that although AtFAR2 is the major enzyme responsible for exine layer functionality, based on subcellular location and expression pattern conditions, AtFAR6 might carry a functional redundancy to $A t \mathrm{~F} A \mathrm{R} 2$.

\section{MATERIALS AND METHODS}

Chemicals. All chemicals, solvents, and lipid standards/references were of reagent grade and, if not otherwise stated, purchased from Merck, Darmstadt, Germany; Sigma, St Louis, MO, USA; or Larodan Fine Chemicals, Malmö, Sweden. BSA was essentially fatty acid free

e-mail: thuydoan@hcmuaf.edu.vn

Abbreviations: ACP, Acyl carrier protein; AtFAR, Arabidopsis thaliana Fatty acid reductase; BSA, Bovine serum albumin; CoA, Coenzyme A; FAR, Fatty acid reductase; GC, Gas chromatography; IPTG, Isopropyl $\beta$-D-1-thiogalactopyranoside; MBP, Maltose binding protein; MS2, Male sterility 2; NADH, Nicotinamide adenine dinucleotide reduced form; NADPH, Nicotinamide adenine dinucleotide phosphate reduced form; TLC, Thin layer chromatography; GFP, Green fluorescent protein; OD, Optical density 
(Sigma). All restriction endonucleases were from Fermentas International Inc. Burlington, Ontario, Canada.

$\left[{ }^{14} \mathrm{C}\right]$-fatty acyl-CoAs were synthesized from their mixed anhydrides according to the method of Sánchez et al. (1973). $\left[{ }^{14} \mathrm{C}\right]$ acyl-ACP was a generous gift from Prof. John Ohlrogge, MSU, East Lansing, USA.

Purification of AtFAR2 expressed in E. coli. The AtFAR2 DNA sequence was amplified by PCR from pET15b harboring AtFAR2 (At3g11980) (Doan et al., 2009) as template. Forward primer FAR2gwF 5'GAG AACCTGTACTTCCAGGGTATGGAGGCTCTC 'TTCT TGA3' and reverse primer FAR2gwR 5'GGGGACCACT'T'TTACAAGAAAGCTGGGTCTTAAGCTCT'TCCT'T'TCAAGACA3' were used to amplify the AtFAR2 coding region; the forward primer contained codons for a TEV cleavage site at the 5' end. In the subsequent amplification, a second forward primer attB1TEV 5'GGGGACAAGT'TTGTACAAAAAAGCAGGCTCGGAGAACCTGTACT'TCCAG3' containing an attB1site, was used together with the reverse primer FAR2gwR. The purified PCR products were subjected to a BP-clonase (Invitrogen) reaction for introduction into pDONR221 (Invitrogen) to create Entry vectors pEntryAtFAR2. The modified coding regions were subsequently moved into pDESTHisMBP (Nallamsetty et al., 2005) via an LR-clonase (Invitrogen) reaction, according to the manufacturer's protocols. pDESTHisMBP harboring AtFAR2, pHisMBP-AtFAR2 were transformed into the E. coli Rosetta (DE3) strain (Novagen) for heterologous protein expression.

For protein expression and purification, $40 \mathrm{ml}$ of $\mathrm{Lu}-$ ria-Bertani broth (LB) media supplemented with $50 \mu \mathrm{g} /$ $\mathrm{ml}$ carbenicillin and $34 \mu \mathrm{g} / \mathrm{ml}$ chloramphenicol were inoculated with a single colony. The cultures were grown overnight at $37^{\circ} \mathrm{C}$ with $240 \mathrm{rpm}$ agitation. Subsequently, the overnight cultures were diluted in $800 \mathrm{ml}$ of antibiotic-supplemented LB media to a final OD 600 of 0.1 and then incubated at $37^{\circ} \mathrm{C}$ with $240 \mathrm{rpm}$ agitation, until OD 600 reached 0.5 to 0.8 . The cultures were transferred to room temperature for $30 \mathrm{~min}$, followed by the addition of isopropyl-1-thio-D-galactopyranoside (IPTG) to a final concentration of $0.5 \mathrm{mM}$ to induce gene expression. Bacteria were grown for an additional 4 to 6 hours at room temperature with $240 \mathrm{rpm}$ agitation before being harvested by centrifugation at $5000 \times g$ and $4^{\circ} \mathrm{C}$ for $20 \mathrm{~min}$. The cell pellets were then flash frozen in liquid nitrogen and stored at $-80^{\circ} \mathrm{C}$ for subsequent protein purification.

For protein purification, the bacterial pellets were resuspended in $36 \mathrm{ml}$ of $100 \mathrm{mM}$ ice cold phosphate buffer, pH 7.0 containing $40 \mathrm{mM}$ imidazole, 10\% (v/v) glycerol, 1x Complete Protease Inhibitor (Roche Applied Science), $5 \mathrm{mM} \mathrm{MgCl}_{2}, 2 \mathrm{mM}$ ATP, $150 \mathrm{mM} \mathrm{KCl}$ and $18 \mu$ Lysonase (Novagen). Prior to homogenization, 1 volume of $0.1 \mathrm{~mm}$ glass beads were added to the cell suspensions and incubated on ice for $30 \mathrm{~min}$. Cells were homogenized using a FastPrep 24 homogenizer (MP Bio) at $4.0 \mathrm{~m} / \mathrm{s}$ for 3 pulses of 30 seconds with $2 \mathrm{~min}$ rest between pulses. The cell lysates were clarified by centrifugation at $3000 \times g$ and $4^{\circ} \mathrm{C}$ for $5 \mathrm{~min}$. The supernatants were further centrifuged at $10000 \times g$ and $4^{\circ} \mathrm{C}$ for $20 \mathrm{~min}$. Collected supernatants were loaded onto a $1 \mathrm{ml}$ HisTrap HP column (GE Healthcare) at a flow rate of $1 \mathrm{ml} / \mathrm{min}$ using BioLogic LP liquid chromatography system (Bio-Rad). The loaded column was then washed with $15 \mathrm{ml}$ of binding buffer $(100 \mathrm{mM}$ Phosphate buffer, pH 7.0 containing $40 \mathrm{mM}$ imidazol and $10 \%$ (v/v) glycerol) at a flow rate of $1 \mathrm{ml} / \mathrm{min}$. Subsequently, a linear gradient of $40 \mathrm{mM}$ to $500 \mathrm{mM}$ imidazole in $20 \mathrm{ml}$ of $100 \mathrm{mM}$ phosphate buffer, $\mathrm{pH} 7.0$, containing $10 \%$ glycerol was applied at a flow rate of $1 \mathrm{ml} / \mathrm{min}$ to elute His-tagged proteins from the column. Eluted proteins were aliquoted, flash frozen in liquid nitrogen and stored at $-80^{\circ} \mathrm{C}$ for further analysis and enzyme assays. Protein concentration was determined using a BCA protein assay (Thermo Scientific) according to the manufacturer's recommendations.

In vitro enzyme assays. The activity of enzyme was determined by measuring the formation of ${ }^{14}[\mathrm{C}]$-fatty aldehyde and ${ }^{14}[\mathrm{C}]$-fatty alcohol from its corresponding ${ }^{14}[\mathrm{C}]$-fatty acyl-CoA or -ACP. To verify the identities of the observed fatty aldehydes and alcohols on TLC, the visualized spots were scraped and analysed by GC in comparison with the unlabelled C16 aldehyde and alcohol standards. To avoid substrate depletion, the assay conditions were adjusted with regard to incubation time and enzyme concentration, such that less than $50 \%$ of substrate was utilized in each assay. Unless otherwise specified, the assays were conducted in $50 \mu \mathrm{l}$ of $100 \mathrm{mM}$ phosphate buffer, $\mathrm{pH} 7.0$, containing $10 \mathrm{mM}$ NADPH, $50 \mu \mathrm{M}{ }^{14}[\mathrm{C}]$ fatty acyl-CoA, $3 \mathrm{mg} / \mathrm{ml}$ BSA, and 0.2 to $0.8 \mu \mathrm{g}$ of protein. After incubation for $30 \mathrm{~min}$ at $30^{\circ} \mathrm{C}$, the reactions were stopped by adding $125 \mu \mathrm{l}$ of chloroform and the total lipids were extracted by the method of Bligh and Dyer (1959). Extracted lipids were subsequently separated on TLC Silica 60 plates (Merck) with hexane/diethyl ether/ acetic acid (55:45:0.5, v/v/v) as the developing solvent. ${ }^{14}[\mathrm{C}]$ on the TLC plates was measured for 15 hours using electronic autoradiography (Instant Imager, Canberra Packard) with 2290 dpm of ${ }^{14}[\mathrm{C}]-\mathrm{C} 18: 1-\mathrm{OH}$ used as the standard control for the quantification.

Transient expression of AtFAR2 in Nicotiana benthamiana leaves. Nicotiana benthamiana plants were grown at $26^{\circ} \mathrm{C} \pm 0.5$ and $60 \%$ relative humidity with $12 \mathrm{~h}$ light $/ 12 \mathrm{~h}$ dark photoperiod $\left(320 \mu \mathrm{mol} / \mathrm{m}^{2} / \mathrm{s}\right)$. Six weeks old plants were used for infiltration.

The coding region of $A t F A R 2$ from the entry vector pEntry-AtFAR2 (see cloning procedure for expression of AtFAR2 in E. coli) was subsequently moved and inserted downstream of a $35 \mathrm{~S}$ promoter in the pXZP393 destination vector (kindly provided by Dr. Xue-Rong Zhou, CSIRO, Australia), via an LR-clonase (Invitrogen) reaction carried out according to the manufacturer's protocols. The resulting binary vectors harboring either AtFAR2, pXZP393-AtFAR2, as well as the P19 and GFP constructs (Wood et al., 2009) kindly provided by Dr. Craig C. Wood, CSIRO, Australia), were introduced into the Agrobacterium tumefaciens strain GV3101::pMP90 (Koncz \& Schell, 1986) by electro-transformation.

The A. tumefaciens cells were grown overnight at $28^{\circ} \mathrm{C}$ with $240 \mathrm{rpm}$ agitation in $5 \mathrm{ml} \mathrm{LB}$ medium supplemented with $50 \mu \mathrm{g} / \mathrm{ml}$ rifampicin, $50 \mu \mathrm{g} / \mathrm{ml}$ gentamycin and $50 \mu \mathrm{g} / \mathrm{ml}$ spectinomycin. For the culture of bacteria harboring P19, $50 \mu \mathrm{g} / \mathrm{ml}$ of kanamycin was used instead of spectinomycin. When the OD reached 0.5 to 1 , acetosyringone was added to a final concentration of $100 \mu \mathrm{M}$ to induce the vir operon of $A$. tumefaciens. Bacteria were grown for an additional 3 hours and then harvested by centrifugation at $3000 \times g$ for $5 \mathrm{~min}$ at room temperature. The harvested cells were subsequently resuspended in $1 \mathrm{ml}$ of an infiltration medium containing $5 \mathrm{mM}$ $\mathrm{MgCl}_{2}, 5 \mathrm{mM}$ MES, pH 5.7, and $100 \mu \mathrm{M}$ freshly added acetosyringone. Prior to infiltration, bacteria harboring AtFAR2 were mixed with bacteria harboring P19 and GFP constructs (also in the infiltration medium), such that the final OD of each bacteria construct combination culture was 0.2. Bacteria harboring a mixture con- 


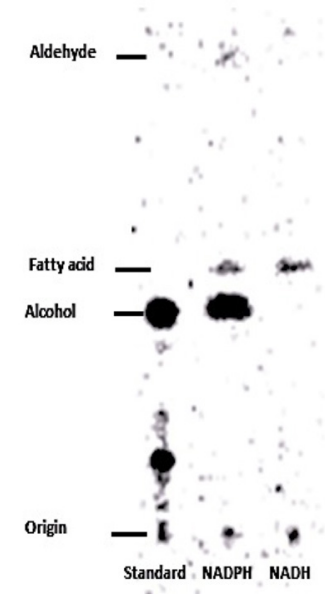

Figure 1. TLC showing the alcohol, aldehyde and free fatty acid produced by AtFAR2 in vitro.

Assays were conducted using $215 \mu \mathrm{g} / \mathrm{ml}$ of AtFAR2 in $100 \mathrm{mM}$ potassium phosphate buffer (pH 7.0), $50 \mu \mathrm{M}$ [14C] 16:0-CoA, $3 \mathrm{mg} /$ $\mathrm{ml} \mathrm{BSA}$ and $10 \mathrm{mM}$ of either NADPH or $\mathrm{NADH}$, at $30^{\circ} \mathrm{C}$ for $30 \mathrm{~min}$.

taining only P19 and GFP constructs were used as the control. Leaves were infiltrated from the abaxial side using a $1 \mathrm{ml}$ syringe without a needle. After 5 days in a growth chamber, the infiltrated leaves were examined for GFP expression. The leaf areas with GFP fluorescence were excised and their fresh weight measured. The harvested leaves were homogenized in $3.75 \mathrm{ml}$ methanol/ chloroform $(2: 1, \mathrm{v} / \mathrm{v})$, followed by lipid extraction using the method of Bligh and Dyer (1959). Extracted lipids corresponding to $100 \mathrm{mg}$ of fresh weight leaf tissue was loaded and separated on TLC Silica 60 plates (Merck) with hexane/diethyl ether/acetic acid $(85: 15: 1, \mathrm{v} / \mathrm{v} / \mathrm{v})$ as the developing solvent. The alcohol spots were located and then scraped and prepared for GC analysis as previously described (Doan et al., 2009).

GC analysis. GC analysis was performed using a Shimadzu gas chromatograph equipped with a flame ionization detector and a capillary column (WCOT fused silica $50 \mathrm{~m} \times 0.32 \mathrm{~mm}$, CP-wax 58 (FFAP)-CB). Helium was used as a carrier gas at a column flow rate of 2.64 $\mathrm{ml} / \mathrm{min}$. Six microliters of the sample were injected into the column. The injection and detector temperatures were $240^{\circ} \mathrm{C}$ and $270^{\circ} \mathrm{C}$, respectively. The gas chromato-

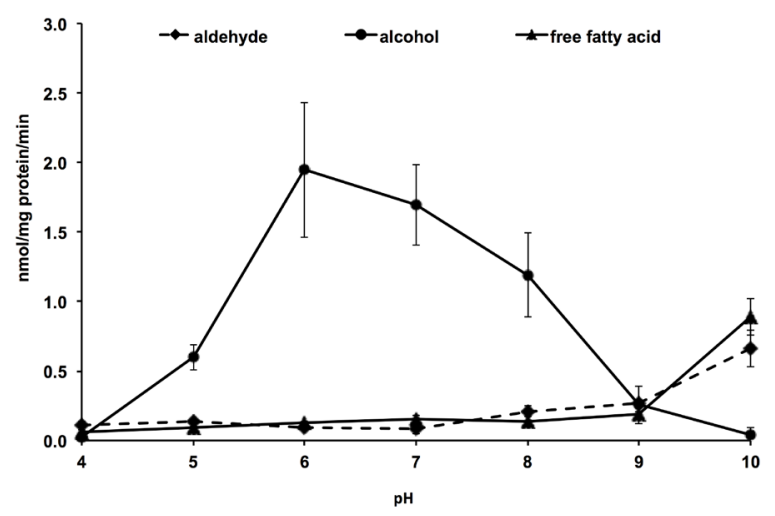

Figure 2. Influence of $\mathrm{pH}$ on the activity of AtFAR2 in vitro.

Assays were conducted in $100 \mathrm{mM}$ citrate buffer ( $\mathrm{pH} 4.0,5.0)$, potassium phosphate buffer $(\mathrm{pH} 6.0,7.0,8.0)$ and glycine buffer $(\mathrm{pH}$ 9.0, 10.0), $10 \mathrm{mM} \mathrm{NADPH}, 50 \mu \mathrm{M}\left[{ }^{14} \mathrm{C}\right] \mathrm{C} 16: 0-\mathrm{CoA}$ and $3 \mathrm{mg} / \mathrm{m}$ $\mathrm{BSA}$, at $30^{\circ} \mathrm{C}$ for $30 \mathrm{~min}$. Error bars indicate $95 \%$ confidence limits. graph oven was programmed at an initial temperature of $100^{\circ} \mathrm{C}$ for $5 \mathrm{~min}$, then the temperature was raised at a rate of $15^{\circ} \mathrm{C} / \mathrm{min}$ up to $240^{\circ} \mathrm{C}$, and then held at $240^{\circ} \mathrm{C}$ for $15 \mathrm{~min}$. The identification of the alcohols was performed by comparing the retention times with authentic standards. Alcohol quantifications were performed by the internal standard method using heptadecanol (3 nmol), which was added prior to lipid extraction.

\section{RESULTS}

\section{Activity of AtFAR2 in vitro}

To avoid the native enzymatic activities of E. coli which could affect the observations, as well as to by-pass the limitation in E. coli endogenous substrates, AtFAR2 was purified from E. coli expressing the AtFAR2 and used for in vitro characterizations. Our results showed that AtFAR2 could utilize C16:0-CoA as a substrate for reduction and required NADPH as the cofactor to produce fatty alcohol while some intermediate aldehyde was released (Fig. 1).

There was no significant difference in the enzyme's activity in the $\mathrm{pH}$ range between 6 and $7(P>0.05)$, the optimal pH range for AtFAR2 activity (Fig. 2). The activity of AtFAR2 was then examined using substrates with different chain lengths, where AtFAR2 showed the highest activity towards C16:0-CoA, approximately 11 times higher in comparison to the activity towards C18:0-CoA (Fig. 3A). AtFAR2 displayed a very low activity with C18:1-CoA, and application of C14:0-CoA as a substrate generated only aldehyde and free fatty acid (Fig. 3A). No activity was observed when using free palmitic acid or ricinoleoyl-CoA as substrates (data not shown). Since AtFAR2 has been determined to be a chloroplast localized enzyme, we conducted assays using C16:0-ACP as a substrate. AtFAR2 showed the ability of utilizing both, C16:0-CoA and C16:0-ACP, although it had a lesser efficiency towards the ACP linked substrate (Fig. 3B).

It should be noted that the difference in the activity of AtFAR2 towards C16:0-CoA and C16:0-ACP was less than the difference in the activity of the enzyme towards C16:0-CoA and C18:0-CoA. Due to the limited availability of C16:0-ACP substrate, we could only conduct the assays using $1.25 \mu \mathrm{M}$ of C16:0-ACP.
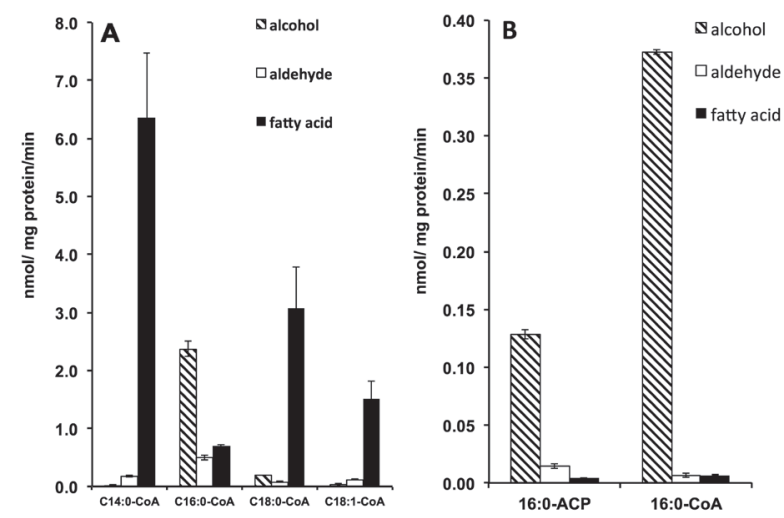

Figure 3. Substrate specificity of purified AtFAR2 in vitro.

(A) Assays were conducted in $100 \mathrm{mM}$ potassium phosphate buffer $(\mathrm{pH} 7.0), 50 \mu \mathrm{M}\left[{ }^{14} \mathrm{C}\right]$ acyl-CoA, $10 \mathrm{mM} \mathrm{NADPH}$ and $3 \mathrm{mg} / \mathrm{ml} \mathrm{BSA}$, at $30^{\circ} \mathrm{C}$ for $30 \mathrm{~min}$. (B) Assays were conducted in $100 \mathrm{mM}$ potassium phosphate buffer $(\mathrm{pH} 7.0), 1.25 \mu \mathrm{M}\left[{ }^{14} \mathrm{C}\right]$ acyl-CoA/ACP, $10 \mathrm{mM}$ NADPH, at $30^{\circ} \mathrm{C}$ for 10 min. Error bars indicate $95 \%$ confidence limits. 

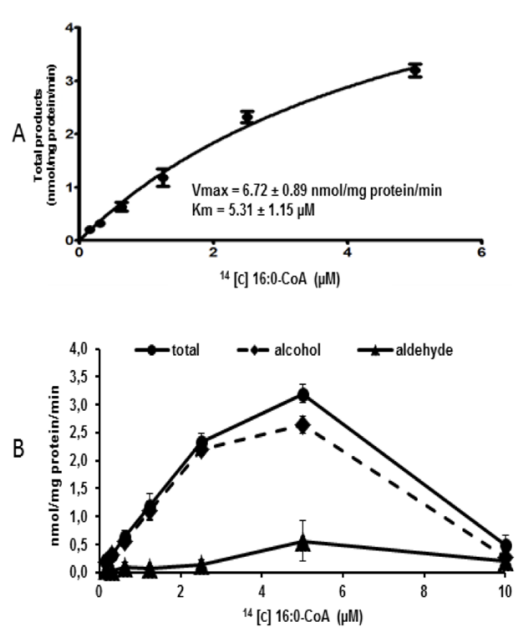

Figure 4. Kinetics of AtFAR2.

Assays were conducted using different concentrations of $\left[{ }^{14} \mathrm{C}\right]$ $16: 0-\mathrm{CoA}$ in $100 \mathrm{mM}$ potassium phosphate buffer ( $\mathrm{pH}$ 7.0) and $10 \mathrm{mM} \mathrm{NADPH}$, at $30^{\circ} \mathrm{C}$ for $10 \mathrm{~min}$. Data was analyzed using GraphpadPrism. Error bars indicate 95\% confidence limits. (A) Michaelis-Menten plot for non-purified enzyme with $\left[{ }^{14} \mathrm{C}\right] 16: 0-$ CoA. (B) Activity of enzyme at different $\left[{ }^{14} \mathrm{C}\right]$ 16:0-CoA concentrations.

\section{Kinetics of AtFAR2 utilizing C16:0-CoA and the effect of BSA on the enzyme activity}

Since AtFAR2 showed its highest specificity towards C16:0-CoA, we determined the enzyme kinetics using various concentrations of $\mathrm{C} 16: 0-\mathrm{CoAs}$ which ranged from $0 \mu \mathrm{M}$ to up to $10 \mu \mathrm{M}$. The results showed that AtFAR2 had a $K_{\mathrm{m}}$ value of $5.31 \mu \mathrm{M}$ and the $V_{\max }$ was determined to be $6.72 \mathrm{nmol} / \mathrm{mg}$ protein/min (Fig. 4A).

We also observed that the activity of the enzyme sharply dropped to almost 0 at a substrate concentration of $10 \mu \mathrm{M}$ (Fig. 4B). Micelle formation of the substrate was the likely cause of the observed effect via a reduction of substrate in free form at higher substrate concentration. To investigate the validity of this assumption, assays were conducted using $50 \mu \mathrm{M}$ of C16:0-CoA (9.4 times higher than $K_{\mathrm{m}}$ value) and BSA was added to different concentrations in the assays. The results showed that BSA had a positive effect on the activity of the enzyme when the substrate concentration was increased. At the tested concentration of C16:0-CoA $(50 \mu \mathrm{M})$, the optimal concentration of BSA for the enzyme activity ranged from 2 to $3 \mathrm{mg} / \mathrm{ml}$ (Fig. 5).

\section{Transient expression of AtFAR2 in Nicotiana benthamiana}

The lipid analysis of $N$. benthamiana leaves harvested five days post-infiltration with the AtFAR2 gene under control of the 35S-promoter, showed that AtFAR2 mainly produced $\mathrm{C} 16: 0-\mathrm{OH}(93 \%$ to $99 \%$ of total fatty alcohols produced) in addition to a small amount of C18:0-OH (Fig. 6). The fatty alcohols produced in the leaves expressing AtFAR2 constituted 0.5 to $0.8 \%$ of the total lipids, while just a trace amount of fatty alcohols was detected in the control leaves. No wax ester that was produced was detected in extracts from the infiltrated leaves 3 to 8 days post-infiltration (data not shown). It was also noticed that, although there were differences in the production of fatty alcohols in the control leaves and the leaves expressing AtFAR2, there was no difference in the appearance and vitality of these leaves (data not shown).

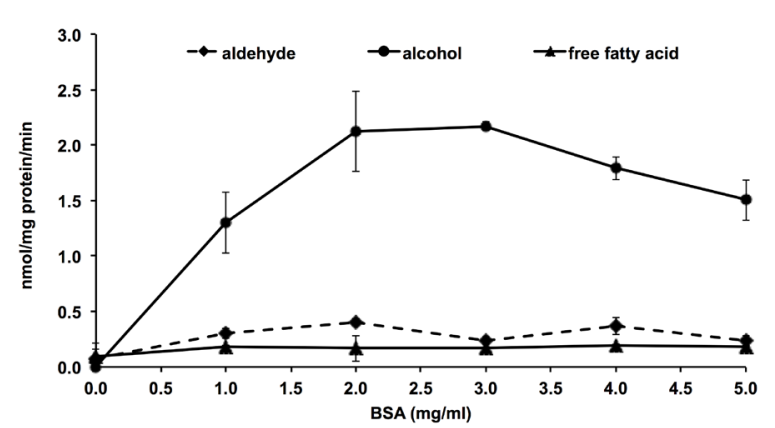

Figure 5. Influence of BSA on the activity of AtFAR2 in vitro. Assays were conducted in $100 \mathrm{mM}$ potassium phosphate buffer $(\mathrm{pH} 7.0), 10 \mathrm{mM} N A D P H$ and $50 \mu \mathrm{M}\left[{ }^{14} \mathrm{C}\right] \mathrm{C} 16: 0-\mathrm{CoA}$, at $30^{\circ} \mathrm{C}$ for $30 \mathrm{~min}$. Error bars indicate $95 \%$ confidence limits.

\section{DISCUSSION}

Fatty alcohols have been found to be of great importance for proper pollen wall formation (Chen et al., 2011; Shi et al., 2011). It has been determined that AtFAR2 has an important role in pollen development i.e. the formation of sporopollenin of exine layers. The analysis of pollen phenotypes suggested that AtFAR2, together with ACOS5, CYP704B1, and CYP703A2, is involved in producing and exporting materials for building the structure of sporopollenin in Arabidopsis (Dobritsa et al., 2009). Specific mutations in genes involved in fatty alcohol biosynthesis e.g. $m s 2$ and $d p w$ cause reduced fertility, sterility or abnormal development of pollen (Aarts et al., 1997; Chen et al., 2011; Shi et al., 2011). It should be noted that plants that are homozygous for a T-DNA insertion mutation in AtFAR2/MS2 (SAIL_92_C07), still produce seeds (Dobritsa et al., 2009) and occasionally a fertile phenotype is also found among the ms 2 mutant plants (Aarts et al., 1997). It is therefore postulated that at least one $A t F A R$ gene can provide redundancy for $A t \mathrm{~F} A \mathrm{R} 2 /$ MS2 to some extent.

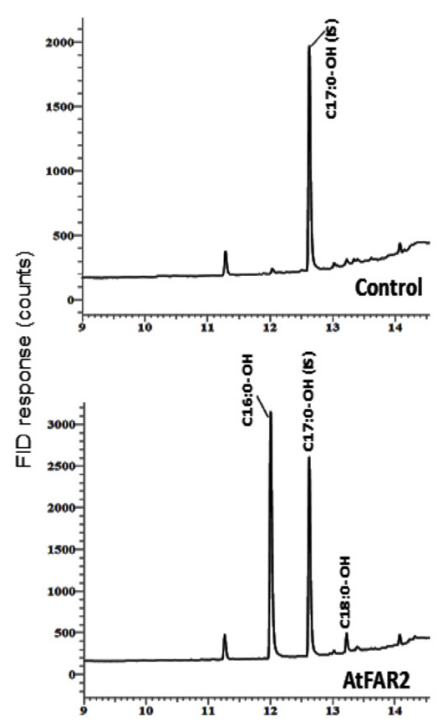

Figure 6. GC analysis of fatty alcohols produced in Nicotiana benthamiana leaves expressing AtFAR2.

The quantity of produced alcohols was calculated using $3 \mathrm{nmol}$ of $\mathrm{C} 17: 0-\mathrm{OH}$ as internal standard. Control: Leaves expressing GFP and P19; AtFAR2: Leaves expressing AtFAR2, GFP and P19. 
Our in vitro characterization of AtFAR2 using the purified enzyme showed that it is a NADPH dependent FAR enzyme with a high specificity towards C16:0CoA/ACP substrates and the $K_{\mathrm{m}}$ value for this enzyme in case of the C16:0-CoA substrate is $5.31 \pm 1.15 \mu \mathrm{M}$.

In vitro characterization of AtFAR2/MS2 has been reported before (Chen et al., 2011). However, in that study, AtFAR2/MS2 showed a very strict specificity towards C16:0-ACP, with a $K_{\mathrm{m}}$ value for this substrate to be $23.3 \pm 1.15 \mu \mathrm{M}$, and no activity towards C16:0-CoA substrate was observed. Accordingly, these results are in contrast to our results with several possible explanations. The affinity of AtFAR2/MS2 to the most preferred substrate (C16:0-ACP) reported by Chen et al. (2011) is four-fold lower than the affinity of this enzyme to the C16:0-CoA substrate as reported here. This difference indicates that the activity of the enzyme described by Chen et al. (2011) is much lower than the activity of the enzyme used in this report. Firstly, protein conformation differences of the purified enzyme could possibly influence the observation of C16:0-CoA utilization reported by Chen et al. (2011). Secondly, our results showed that no enzyme activity was observed when free palmitic acid (C16:0) was used in the assay, indicating that this enzyme could only utilize activated fatty acids (ACP or CoA) as substrates and not the free fatty acids. Therefore, the degradation of $\mathrm{C} 16: 0-\mathrm{CoA}$ into free palmitic acid in the assays by Chen et al. (2011) could potentially be another cause for the observed no metabolic activity of the enzyme towards C16:0-CoA.

Finally, the results presented here showed that AtFAR2/MS2 could only utilize the free form of the substrate and not the micelle form. Under the test conditions, there was almost no enzyme activity at $10 \mu \mathrm{M}$ of C16:0-CoA substrate and enzymatic activity at higher C16:0-CoA concentrations was only observed in the presence of BSA in the assay. Assuming that the $K_{\mathrm{m}}$ value of AtFAR2/MS2 towards C16:0-ACP $(23.3 \pm 1.15$ $\mu \mathrm{M})$ is similar to that of $\mathrm{C} 16: 0-\mathrm{CoA}$, according to our results, C16:0-CoA substrate would then be trapped in the micelle form at this concentration $(23.3 \pm 1.15 \mu \mathrm{M})$ and therefore be inaccessible to AtFAR2/MS2. Whereas, the activity of the enzyme towards C16:0-ACP at this concentration might not be affected since it is known from the literature that the critical concentration of C16:0-ACP for micelle formation is much higher than that of 16:0-CoA (Lueking \& Goldfine, 1975).

Among eight AtFAR homologues in the Arabidopsis genome, the biological functions of most AtFARs have been discovered, i.e. AtFAR3/CER4 produces C24-C28 alcohols for cuticular wax esters, the group of AtFAR1, AtFAR4, and AtFAR5 enzymes is involved in the production of C18 to C22 alcohols of suberin (Rowland et al., 2006; Domergue et al., 2010; Rowland \& Domergue, 2012), and AtFAR7 and AtFAR8 are suspected to be pseudogenes due to their low expression and activity (Domergue et al., 2010; Chacon et al., 2013). The results obtained in our experiments and those reported by Chen et al. (2011) clarified that AtFAR2 is the enzyme used for the production of C16:0-alcohol in plastids of Arabidopsis. Accordingly, the differences in the fatty alcohol profiles produced by other functionally known AtFAR enzymes, as compared to that produced by AtFAR2, exclude the possibility that they would be functionally complementary to AtFAR2.

The properties of AtFAR2/MS2 found in this study are very similar to those that have been reported for AtFAR6. AtFAR6 has been found to be a chloroplast localized enzyme with high specificity towards both,
C16:0-ACP and C16:0-CoA substrates (Doan et al., 2012). AtFAR6 is the only additional Arabidopsis FAR that is chloroplast localized and displayed similar substrate specificity to those of AtFAR2, as well as similar functional aspects under varying substrate and BSA concentrations under in vitro conditions. This could indicate a functional redundancy between AtFAR2/MS2 and AtFAR6, and that AtFAR6 could thus provide the reductase activity, reducing the impact to fertility in ms 2 mutants. Further supporting this hypothesis are similar expression patterns in anthers of both, AtFAR2/MS2 and AtFAR6 (Aarts et al., 1997; Chen et al., 2011). Ultimately, the expression of AtFAR6 in the ms 2 mutant, as well as the analysis of the atfar6/ms2 double mutant, should clarify their relationship and possible functional redundancy.

\section{Acknowledgements}

The Swedish International Development Cooperation Agency (SIDA/SAREC) and Nong Lam University are gratefully acknowledged for financial supports. This work is part of ICON, a European Commission sponsored FP7 project.

\section{REFERENCES}

Aarts MGM, Hodge R, Kalantidis K, Florack D, Wilson ZA, Mulligan BJ, Stiekema WJ, Scott R, Pereira A (1997) The Arabidopsis MALE STERILITY 2 protein shares similarity with reductases in elongation/condensation complexes. The Plant Journal 12: 615-623. doi:10.1046/j.1365-313X.1997.00615.x.

Bligh E, Dyer W (1959) A rapid method of total lipid extraction and purification. Can J Physiol Pharmacol 37: 911-917. doi:10.1139/o59099 .

Chacon MG, Fournier AE, Tran F, Dittrich-Domergue F, Pulsifer IP, Domergue F, Rowland O (2013) Identification of amino acids conferring chain length substrate specificities on fatty alcohol-forming reductases FAR5 and FAR8 from Arabidopsis thaliana. I Biol Chem 288: 30345-30355. doi:10.1074/jbc.M113.499715.

Chen W, Yu X-H, Zhang K, Shi J, Schreiber L, Shanklin J, Zhang D (2011) Male sterile 2 encodes a plastid-localized fatty acyl ACP reductase required for pollen exine development in Arabidopsis thaliana. Plant Physiol 157: 842-853. doi:10.1104/pp.111.181693.

Doan TTP, Carlsson AS, Hamberg M, Bülow L, Stymne S, Olsson P (2009) Functional expression of five Arabidopsis fatty acylCoA reductase genes in Escherichia coli. J Plant Physiol 166: 787-796. doi:10.1016/j.jplph.2008.10.003.

Doan TTP, Domergue F, Fournier AE, Vishwanath SJ, Rowland O, Moreau P, Wood CC, Carlsson AS, Hamberg M, Hofvander P (2012) Biochemical characterization of a chloroplast localized fatty acid reductase from Arabidopsis thaliana. Biochim Biophys Acta (BBA) - Molecular and Cell Biology of Lipids 1821: 1244-1255. http://dx.doi. org/10.1016/j.bbalip.2011.10.019.

Dobritsa AA, Shrestha J, Morant M, Pinot F, Matsuno M, Swanson R, Moller BL, Preuss D (2009) CYP704B1 is a long-chain fatty acid \{omega\}-hydroxylase essential for sporopollenin synthesis in pollen of Arabidopsis. Plant Physiol 151: 574-589. doi:10.1104/pp.109.144469.

Domergue F, Vishwanath SJ, Joubes J, Ono J, Lee JA, Bourdon M, Alhattab R, Lowe C, Pascal S, Lessire R, Rowland O (2010) Three Arabidopsis fatty acyl-coenzyme A reductases FAR1 FAR4 and FAR5 generate primary fatty alcohols associated with suberin deposition. Plant Physiol 153: 1539-1554. doi:10.1104/pp.110.158238.

Kolattukudy PE (1970) Reduction of fatty acids to alcohols by cellfree preparations of Euglena gracilis. Biochemistry 9: 1095-1102. doi:10.1021/bi00807a007.

Koncz C, Schell J (1986) The promoter of T L-DNA gene 5 controls the tissue-specific expression of chimaeric genes carried by a novel type of Agrobacterium binary vector. Mol General Genet MGG 204: 383-396. doi:10.1007/BF00331014.

Lueking DR, Goldfine H (1975) The involvement of guanosine 5-diphosphate-3-diphosphate in the regulation of phospholipid biosynthesis in Escherichia coli. Lack of ppGpp inhibition of acyltransfer from acyl-ACP to sn-glycerol 3-phosphate. J Biol Chemi 250: 4911. doi:250/13/4911.long.

Metz JG, Pollard MR, Anderson L, Hayes TR, Lassner MW (2000) Purification of a jojoba embryo fatty acyl-coenzyme A reductase and expression of its cDNA in high erucic acid rapeseed. Plant Physiol 122: 635-644. http://dx.doi.org/10.1104/pp.122.3.635.

Nallamsetty S, Austin BP, Penrose KJ, Waugh DS (2005) Gateway vectors for the production of combinatorially-tagged His6-MBP fu- 
sion proteins in the cytoplasm and periplasm of Escherichia coli. pp 2964-2971. Cold Spring Harbor Laboratory Press.

Pollard M, Beisson F, Li Y, Ohlrogge JB (2008) Building lipid barriers: biosynthesis of cutin and suberin. Trends Plant Sci 13: 236-246. doi:10.1016/j.tplants.2008.03.003.

Post-Beittenmiller D (1996) Biochemistry and molecular biology of wax production in plants. Ann Rev Plant Physiol Plant Mol Biol 47: 405-430. doi:10.1146/annurev.arplant.47.1.405.

Rowland O, Domergue F (2012) Plant fatty acyl reductases: Enzymes generating fatty alcohols for protective layers with potential for industrial applications. Plant Sci 19-194: 328-338. doi:10.1016/j.plantsci.2012.05.002.

Rowland O, Zheng H, Hepworth SR, Lam P, Jetter R, Kunst L (2006) CER4 encodes an alcohol-forming fatty acyl-coenzyme A reductase involved in cuticular wax production in Arabidopsis. Plant Physiol 142: 866-877. doi:10.1104/pp.106.086785.

Shi J, Tan H, Yu X-H, Liu Y, Liang W, Ranathunge K, Franke RB, Schreiber L, Wang Y, Kai G, Shanklin J, Ma H, Zhang D (2011)
Defective pollen wall is required for anther and microspore development in rice and encodes a fatty acyl carrier protein reductase. The Plant Cell 23: 2225-2246. doi:10.1105/tpc.111.087528.

Vioque J, Kolattukudy PE (1997) Resolution and purification of an aldehyde-generating and an alcohol-generating fatty acyl-CoA reductase from pea leaves (Pisum sativum L.). Arch Biochem Biophys 340: 64-72. doi:10.1006/abbi.1997.9932.

Wang A, Xia Q, Xie W, Dumonceaux T, Zou J, Datla R, Selvaraj G (2002) Male gametophyte development in bread wheat (Triticum aestivum L.): molecular cellular and biochemical analyses of a sporophytic contribution to pollen wall ontogeny. The Plant Journal 30: 613-623. doi:10.1046/j.1365-313X.2002.01313.x.

Wood CC, Petrie JR, Shrestha P, Mansour MP, Nichols PD, Green AG, Singh SP (2009) A leaf-based assay using interchangeable design principles to rapidly assemble multistep recombinant pathways. Plant Biotechnol J 7: 914-924. doi:10.1111/j.1467-7652.2009.00453.x. 